\title{
Application of a marker of ciliated epithelial cells to gynaecological pathology
}

\author{
Mary T Comer, Alison C Andrew, Henry J Leese, Ludwik K Trejdosiewicz, \\ Jennifer Southgate
}

\begin{abstract}
Background-The assessment of neoplastic disease in gynaecological histopathology can be complicated by the high incidence of metaplasia seen in tissues of the female genital tract. There is a need to identify specific tissue markers which can be applied in routine histopathological practice.

Aim-To examine the clinical potential of a monoclonal antibody, LhS28, which reacts with basal bodies of ciliated epithelial cells.

Methods-A panel of normal and pathological gynaecological tissues was processed and labelled with LhS28.

Results-LhS28 immunoreactivity was found in the normal Fallopian tube where it was confined to ciliated rather than secretory epithelial cells. In the remaining specimens, LhS28 was associated exclusively with ciliated cells in tubal metaplasias of the cervix and endometrium and in benign serous lined inclusion cysts. Conclusions-LhS28 may be a valuable marker for identifying metaplasia of tubal type and may find application in distinguishing tubal metaplasia from low grade cervical glandular intraepithelial neoplasia.

(f Clin Pathol 1999;52:355-357)
\end{abstract}

Imperial Cancer

Research Fund Cancer

Medicine Research

Unit, St James's

University Hospital,

Leeds LS9 7TF, UK

M T Comer

L K Trejdosiewicz

J Southgate

Histopathology, The General Infirmary at Leeds, Leeds LS1 3EX, UK

A C Andrew

Department of Biology, PO Box 373, University of York, York YO1 5YW, UK H J Leese

Correspondence to: Dr Southgate.

email:

j.southgate@leeds.ac.uk

Accepted for publication 15 December 1998

The paramesonephric duct arises during embryological development as an invagination and later canalisation of the coelomic epithelial lining into the adjacent subcoelomic mesenchymal tissue. There is ultimately partial fusion with the duct from the other side to give rise to the Fallopian tube, the body of the uterus, and the endocervix, which are lined by serous, endometrial, and mucinous epithelia, respectively. These epithelia are termed "Müllerian," and metaplasia from one type to another within the female genital tract is well recognised. ${ }^{12}$

There is a well documented occurrence of non-neoplastic and neoplastic lesions in structures derived from outside the Müllerian ducts which has led to the concept of a "secondary Müllerian system." Such sites include the surface of the ovary, the peritoneum, and the lymph nodes. The mesothelial lining of the peritoneum has the capacity to differentiate toward Müllerian epithelium from which benign, atypically proliferating/borderline or frankly malignant tumours may develop. ${ }^{3-5}$

The capacity to identify Müllerian epithelia in sites within and distant to the female genital tract and in particular to distinguish between non-neoplastic and neoplastic conditions is valuable in histopathological practice. While the recognition of tubal type epithelium is normally possible on haematoxylin and eosin stained histological sections, there are situations when confirmation of its presence could prove helpful. These include differentiating tubal metaplasia from cervical low grade glandular intraepithelial neoplasia and identifying lesions in lymph nodes as benign serous lined inclusions/endosalpingiotic foci (particularly in hysterectomy specimens removed for adenocarcinoma). ${ }^{1256}$ The benign nature of these lesions, in the context of the correct cytological and architectural detail, is supported by the identification of ciliated cells, which are rarely, if ever, observed in adenocarcinomas.

During the course of basic research into the cell biology and physiology of the epithelium of the human Fallopian tube, we identified a monoclonal antibody, LhS28, which appeared to show highly restricted immunoreactivity with ciliated Fallopian tube epithelial cells. ${ }^{78}$ Our aims in this study were to determine whether expression of the antigen recognised by LhS28 was associated with pathological conditions of the secondary Müllerian system and the female genital tract outside the Fallopian tube.

\section{Methods}

Specimens of normal and pathological tissues were fixed and processed into paraffin wax using routine procedures. Where appropriate, tissue specimens were obtained from archival sources. Normal tissues included endometrium (4), cervix (2), vagina (3), and Fallopian tube (23). The spectrum of benign disease comprised tubal metaplasia of cervix (2) and endometrium (2), endosalpingiosis of lymph node (2), and serous lined inclusion cysts of the ovary (2). Specimens of borderline disease included serous tumours of ovary (3) and one case of peritoneal borderline serous tumour. The malignant tissues studied consisted of serous adenocarcinoma of the ovary (4) and 
metastatic serous adenocarcinoma of the omentum (1).

Paraffin wax embedded sections of $5 \mu \mathrm{m}$ thickness were cut, dewaxed, rehydrated through graded alcohols into water, and microwaved in $10 \mathrm{mM}$ citrate buffer, $\mathrm{pH} 6.0$, for 13 minutes. Sequential blocking of sections was carried out in $20 \%$ (vol/vol) rabbit serum and an avidin/biotin blocking kit used according to the manufacturer's instructions (Vector Laboratories).

Sections were incubated sequentially in primary antibody for one hour, biotinylated goat anti-mouse immunoglobulin (Dako) for 30 minutes, and ABC complex (Dako) for 30 minutes, with washing between each step. Antibody binding was visualised by a diaminobenzidine substrate reaction and enhanced with imidazole. Slides were counterstained in haematoxylin, dehydrated, cleared, and mounted in DPX. Tris buffered saline (50 $\mathrm{mM} ; \mathrm{pH}$ 7.6) was used throughout and all incubations were carried out at ambient temperature. Positive and negative specificity controls were used throughout. ${ }^{9}$

\section{Results}

Immunoreactivity with $\mathrm{LhS} 28$ was consistently and exclusively confined to ciliated epithelial cells. The antigen was localised to a cytoplasmic band lying subjacent to the apical membrane and in the region of the ciliary bodies. No reactivity was found on any non-ciliated cell type, including the secretory epithelial cells of the Fallopian tube and epithelial cells of the cervix and endometrium. In some specimens of "normal" endometrium, rare ciliated epithelial cells were positive within glands, reflecting the presence of focal metaplasia.

In all specimens, LhS28 positivity was only associated with ciliated cells. Positive labelling with LhS28 was found in tubal metaplasia of the cervix and endometrium, serous lined inclusion cysts of the ovary, endosalpingiosis within lymph nodes, and borderline serous tumours of the ovary (fig 1). In serous lined inclusion cysts of the ovary and endosalpingiosis within lymph nodes, LhS28 positive cells were sparse, but where positive showed intense unequivocal labelling, allowing positive identification of the small number of ciliated cells. In serous borderline tumours, a large proportion of cells were ciliated and interspersed by LhS28 negative non-ciliated cells. Invasive serous adenocarcinomas were negative and no LhS28 positive cells were found in pelvic or peritoneal specimens containing a non-ciliated, secretory type Müllerian metaplasia.

\section{Discussion}

We have identified a novel antigen, recognised by antibody LhS28, which is expressed only by ciliated epithelial cells. In another study, we have shown that the subcellular localisation of the antigen is associated with the ciliary basal bodies which give rise to the cilia on the apical cell surface. ${ }^{7}$ The highly restricted nature of the antigen makes it a useful marker for ciliated
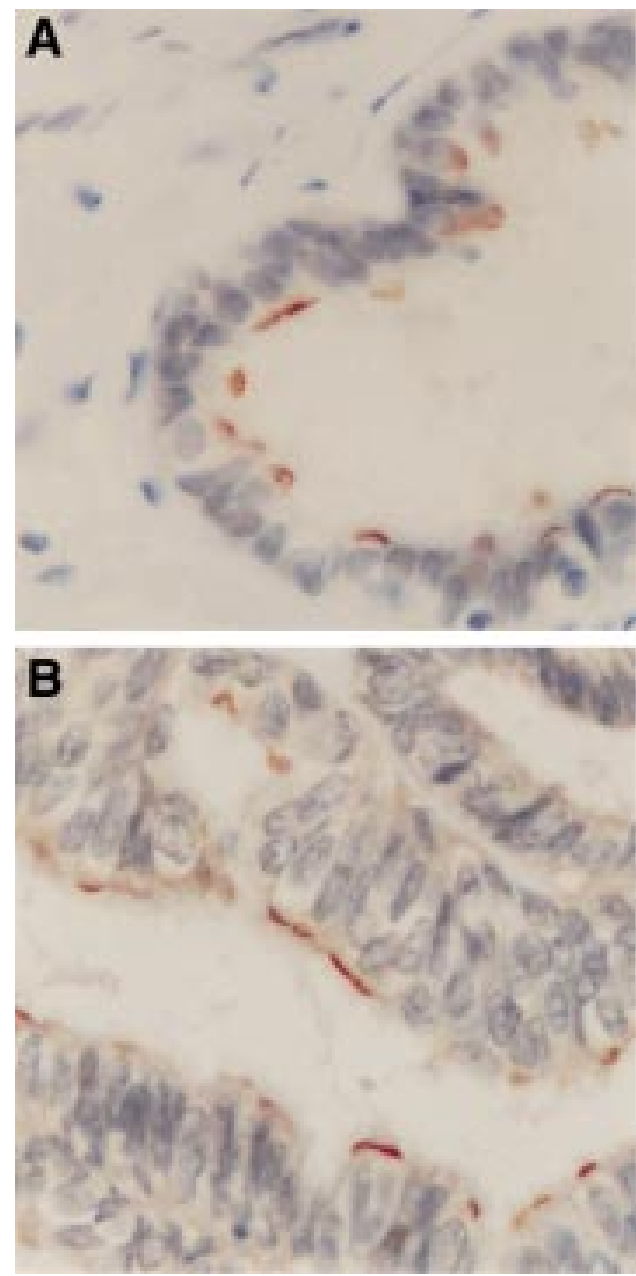

Figure 1 LhS28 showing characteristic staining pattern of ciliated epithelial cells on $(A)$ serous lined inclusion cyst of the ovary and $(B)$ serous borderline tumour of the ovary, showing multilayered epithelium.

epithelial cell types, particularly in conditions where ciliated cells are rare, or the histology is obscured by an inflammatory reaction or by poor tissue preservation. In such situations, the use of an antibody marker to positively distinguish ciliated cells could be a useful adjunct to more conventional histological examination.

From this study, we would suggest that LhS28 has potential as a diagnostic marker for distinguishing between benign metaplastic conditions with a tubal epithelial phenotype and glandular neoplasia, especially where benign conditions arise in extragenital sites such as lymph nodes. Positive immunolabelling with LhS28 confirmed the presence of at least some ciliated cells in these benign conditions, while no such cells were identified in invasive serous adenocarcinomas. Thus LhS28 may serve in the categorisation of tumours of different malignant potential, although further study will be needed to substantiate this.

This study was funded by a small research grant from the Research and Development Directorate of the NHS Executive Northern and Yorkshire Region. We are also grateful to the Medical Research Council for financial support of this work. 
1 Jonasson JG, Wang HH, Antonioli DA, et al. Tubal metaplasia of the uterine cervix: a prevalence study in patients with gynecologic pathologic findings. Int $\mathcal{f}$ Gynecol Pathol

2 Oliva E, Clement PB, Young RH. Tubal and tuboendometrioid metaplasia of the uterine cervix. Anat Patho 1995;103:618-23.

3 Scully RE. Pathology of ovarian cancer precursors. 7 Cell Biochem 1995;23:208-18.

4 Link CJ, Reed E, Sarosy G, et al. Borderline ovarian tumors. Am F Med 1996;101:217-25.

5 Fox H. Primary neoplasia of the female peritoneum. Histopathology 1993;23:103-10.
6 Ducatman BS, Wang HH, Jonasson JG, et al. Tubal metaplasia: a cytologic study with comparison to other neoplastic and non-neoplastic conditions of the endocer-

7 Comer MT, Shires M, Goode NP, et al. Expression of a novel protein specific to the basal bodies of ciliated epithelium. Histochem f 1999;31:39-43

8 Comer MT, Leese HJ, Southgate J. Induction of a differentiated ciliated cell phenotype in primary cultures of Fallopian tube epithelium. Hum Reprod 1998;13:3114-20.

9 Southgate J, Trejdosiewicz LK. Immunolabelling of cells and tissue approaches and pitfalls. Hum Reprod 1997; 12(suppl):65-75.

\section{The Royal College of Pathologists "The Best" of the College Symposia}

Academic activities, Continuing Professional Development, and Blackwell Healcare Communications are publishing a CD-ROM containing highlights of past College Symposia.

This CD-ROM is approved for CPD credits and is of general interest to pathologists. It covers a wide range of topical issues, with lectures entitled:

- Allergy and asthma

- Peanut allergy

- A practical approach to unexpected infant death

- Vitamin K prophylaxis: can we ever reach a consensus?

- Epidemiology of adverse effects of "designer drugs"

- Multi-drug resistance modifiers: an alternative approach

- Idiopathic myelofibrosis: pathogenesis to treatment

- Adhesion molecules in pathology

- Chromosomal changes and cancer

- Interpretation of injury in road traffic accidents

- Reporting of cervical biopsies in the context of the cervical screening programmes

- The metastatic process: its biological basis

- Human papilloma virus infection

- The hepatitis virus

- Alcoholic liver disease

The CD-ROM will cost you $£ 30$ for a personal copy or $£ 120$ for an institutional copy with multiple user licence. To order a copy, call 01719305862. 